\title{
Composición y estructura de las comunidades vegetales del rancho EI Durangueño, en la Sierra Madre Occidental, Durango, México
}

\author{
Structure and composition of the vegetation communities of El Durangueño Ranch, in the \\ Sierra Madre Occidental, Durango, Mexico
}

\author{
Elizabeth E. Aragón-Piña ${ }^{1 *}$, Alfredo Garza-Herrera ${ }^{1}$, M. Socorro González-Elizondo ${ }^{2}$ e Isolda Luna-Vega ${ }^{3}$ \\ ${ }^{1}$ Centro de Ecología Regional, A.C. Blvd. Durango 309 A, Col. Valle del Sur, Durango 34120 Durango, México. \\ ${ }^{2}$ Centro Interdisciplinario de Investigación para el Desarrollo Integral Regional (CIIDIR-IPN) Durango. Sigma 119, Fracc. 20 de Noviembre II, \\ Durango 34220, Durango, México. \\ ${ }^{3}$ Departamento de Biología Evolutiva, Facultad de Ciencias, Universidad Nacional Autónoma de México. Apartado postal 70-399, Coyoacán 04510, \\ México, D.F., México. \\ *Correspondencia: eeapliz@hotmail.com
}

\begin{abstract}
Resumen. Se analizó la estructura y la composición florística de un bosque templado de la Sierra Madre Occidental (SMO) en el estado de Durango. El área de estudio se ubica en el rancho El Durangueño, cuya vegetación es representativa de la vertiente oriental de la SMO. El muestreo fue al azar, en puntos establecidos en 3 tipos de vegetación dominantes: bosque de encino-pino, bosque de pino-encino y pastizal. Las características estructurales de la vegetación indican que los sitios de muestreo presentan gran heterogeneidad, encontrándose hasta 26 especies en los pastizales, 31 en los bosques de encino-pino y 22 en los de pino-encino, siendo éste el estrato que presentó mayor número de especies (76 \%). Los árboles tienen mediana estatura, con densidades similares a otras localidades de la sierra. Los bosques de encino-pino presentaron los valores más altos de diversidad. En los sitios censados habitan 12 especies de plantas endémicas de México, 6 de las cuales lo son para la SMO. Psacalium cronquistiorum B.L. Turner (Asteraceae) se localiza únicamente en Durango y 7 especies están incluidas en la Lista roja de la IUCN. Aunque no hay referencias de incendios en los bosques del área, la amplia distribución de matorrales de Q. striatula sugiere que éstos pueden haber ocurrido en el pasado reciente.
\end{abstract}

Palabras clave: bosque de encino, bosque de pino, pastizal, cuadrantes centrados en un punto.

\begin{abstract}
Structure and floristic composition of a temperate forest of the Sierra Madre Occidental (SMO), in the state of Durango, Mexico, were analyzed in order to characterize the different plant strata. The study area is located at El Durangueño Ranch, with vegetation representative of the eastern slopes of the SMO. The area includes 3 dominant vegetation types: oak-pine forest, pine-oak forest and grassland. Floristic composition corresponds to semidry temperate forests and in smaller proportion to humid temperate forests of northern Mexico. Structural characteristics indicate that the sites present great heterogeneity, 26 species of grasslands, 31 in the oak-pine and 22 in the pine-oak, with the stratum under which presented more species 76. The trees are medium sized and the densities are similar to other sites of this mountain range. Oak-pine forests have the highest values of diversity and were similar to those registered in other areas of the SMO. There are 12 species endemic to Mexico, from which 6 are endemic to the SMO, and Psacalium cronquistiorum B.L. Turner (Asteraceae) is endemic of Durango. Seven species are included in the Red list of the IUCN. Grasslands have high floristic richness, combining species typical of the grasslands of lower elevations with species of temperate forests. Although there is no reference to fires in the forests of the area, the wide distribution of Quercus striatula scrub may indicate disturbance attributed to fires in the recent past.
\end{abstract}

Key words: oak-pine forest, pine-oak forest, grassland, point center quarter method.

\section{Introducción}

Los bosques templados constituyen grandes reservorios de la diversidad biológica de México

Recibido: 12 mayo 2009; aceptado: 06 febrero 2010
(Mittermeier y Mittermeier, 1992). En particular, la Sierra Madre Occidental (SMO), ubicada en la región florística Mesoamericana de Montaña (Rzedowski, 1978), es una provincia florística y fisiográfica que representa el 30\% del territorio de México y está considerada un importante centro de diversificación de especies de pinos y encinos, ya que en general los bosques templados de este país 
contienen más del $50 \%$ de las especies de pino y el 33\% de las especies de encinos del mundo (Rzedowski, 1978; González y González, 1995; Styles, 1998; Challenger, 1998; Valencia-Ávalos, 2004). En particular, los bosques de pino-encino resguardan una gran riqueza de especies de plantas, resultado de las especies del sotobosque y un alto grado de endemismo (Rzedowski, 1978; Bye, 1995; Sánchez et al., 2003).

La importancia de la SMO no sólo estriba en su alta diversidad sino también porque las especies de pinos y encinos son los árboles más representativos y de mayor interés económico en los ecosistemas de México y del mundo (Sánchez et al., 2003). Dentro de esta provincia se ubica el estado de Durango (71.5\% de su superficie) que está considerado como la más importante reserva nacional forestal, generando entre el 25 y $30 \%$ de la producción maderable, con un total de 1.78 millones de $\mathrm{m}^{3}$ de madera en rollo anuales (SEMARNAT, 2009). Por otra parte, estos bosques son una fuente importante de servicios ambientales.

La SMO es una provincia de gran interés ecológico por su alta heterogeneidad ambiental, debido a que presenta una gran diversidad fisiográfica y climática; en ella existen ambientes fríos en las cimas, condiciones húmedas en las regiones occidentales y sudoccidentales y semisecas en las partes norte y noroeste (Challenger, 1998). La inclinación y la orientación de las laderas, el tipo y profundidad del suelo y la compleja historia geotectónica del área han permitido que se desarrollen distintas comunidades bióticas que producen un intrincado mosaico de vegetación dentro de áreas relativamente cercanas o pequeñas con gran variación altitudinal, por lo que se ha sugerido que podría existir un gran número de especies endémicas de plantas y animales (Challenger, 1998).

No obstante, son pocos los estudios taxonómicoecológicos de las especies de plantas que componen los bosques templados de la SMO. Martínez (1945) describió los pinos de la sierra de Durango; Maysilles (1959), Gordon (1968), Passini (1985), Madrigal (1977), González et al. (1991, 1993), Márquez y González (1998) y González et al. (2007) analizaron la distribución de algunos pinos, la estructura y composición florística de la vegetación, así como su correlación con algunas variables físicas; los pastizales fueron estudiados por Gentry (1957) y Herrera (2001).

Sin embargo, debido a la compleja superficie y heterogeneidad de la vegetación de este macizo montañoso, se requiere la inclusión de otros sitios, en especial los que son zonas de transición de la vegetación (ecotonos), donde se entremezclan elementos del bosque templado y de zonas semiáridas.

Este trabajo tiene como objetivos caracterizar la composición florística, detectar las especies importantes para la conservación y/o protección, así como determinar la distribución y la estructura de la vegetación de un bosque templado localizado en la Sierra Madre Occidental (SMO), en el estado de Durango.

\section{Materiales y métodos}

Área de estudio. El Rancho El Durangueño se ubica en el estado de Durango, en el municipio de Canatlán, a 54 $\mathrm{km}$ en línea recta de la capital del estado $\left(24^{\circ} 27^{\prime} 31^{\prime \prime} \mathrm{N}\right.$ y $104^{\circ} 55^{\prime} 55^{\prime}$ ' O; Fig. 1, Cuadro 1). La altitud promedio es de $2500 \mathrm{~m}$ (2 400 a $2820 \mathrm{~m}$, Garza et al., 2005) y para el área muestreada entre 2456 y $2554 \mathrm{~m}$. El predio es una propiedad privada que consta de 10378 ha. De acuerdo con la clasificación de Köppen adaptada para México, el clima es $\mathrm{C}(\mathrm{b})\left(\mathrm{w}_{2}\right)$, semifrío con lluvias en verano y precipitaciones invernales entre el 5 y el $10.2 \%$ del total anual; la precipitación media anual varía de 800 a $1000 \mathrm{~mm}$. La temperatura media anual fluctuó entre $3.5^{\circ}$ y $21.5^{\circ} \mathrm{C}$, y la precipitación media anual fue de $505 \mathrm{~mm}$, monitoreada durante el estudio (2005 a 2006) con sensores datalogger.

El Durangueño se ubica en la provincia fisiográfica y florística Sierra Madre Occidental (Rzedowski, 1978; González et al., 2007) y forma parte de la región hidrológica prioritaria 40 Río Nazas (Arriaga et al., 2000, 2002). La fisiografía del predio está conformada principalmente por lomeríos con pendientes complejas que oscilan entre el $25 \%$ y el $35 \%$, así como mesetas altas con pendientes uniformes de 0 a 10\% (terrenos ondulados) y en menor proporción se encuentran áreas con pendientes pronunciadas, alcanzando un $45 \%$ de las consideradas como escarpadas y que representan un $10 \%$ de la superficie del predio.

Los suelos son regosoles eútricos, feozems háplicos y litosoles, todos de textura mediana, según el sistema de clasificación de la FAO-UNESCO (1974), adaptada para México por DETENAL (1972). Estos suelos son de color negro o grisáceo con un alto contenido de materia orgánica, de buena fertilidad y moderadamente ácidos. Las rocas son ígneas extrusivas ácidas, principalmente de basalto y toba riolítica, además de depósitos aluviales y coluviales. Los tipos de vegetación dominantes son los bosques de encino-pino y de pino-encino en las partes más altas, correspondiendo a los tipos de bosques existentes en la vertiente interior de la SMO de Durango (Garza et al., 2005). No existen registros de incendios forestales recientes en la zona; el último que se presentó dentro del predio fue en 1965, mientras que en predios aledaños hubo 


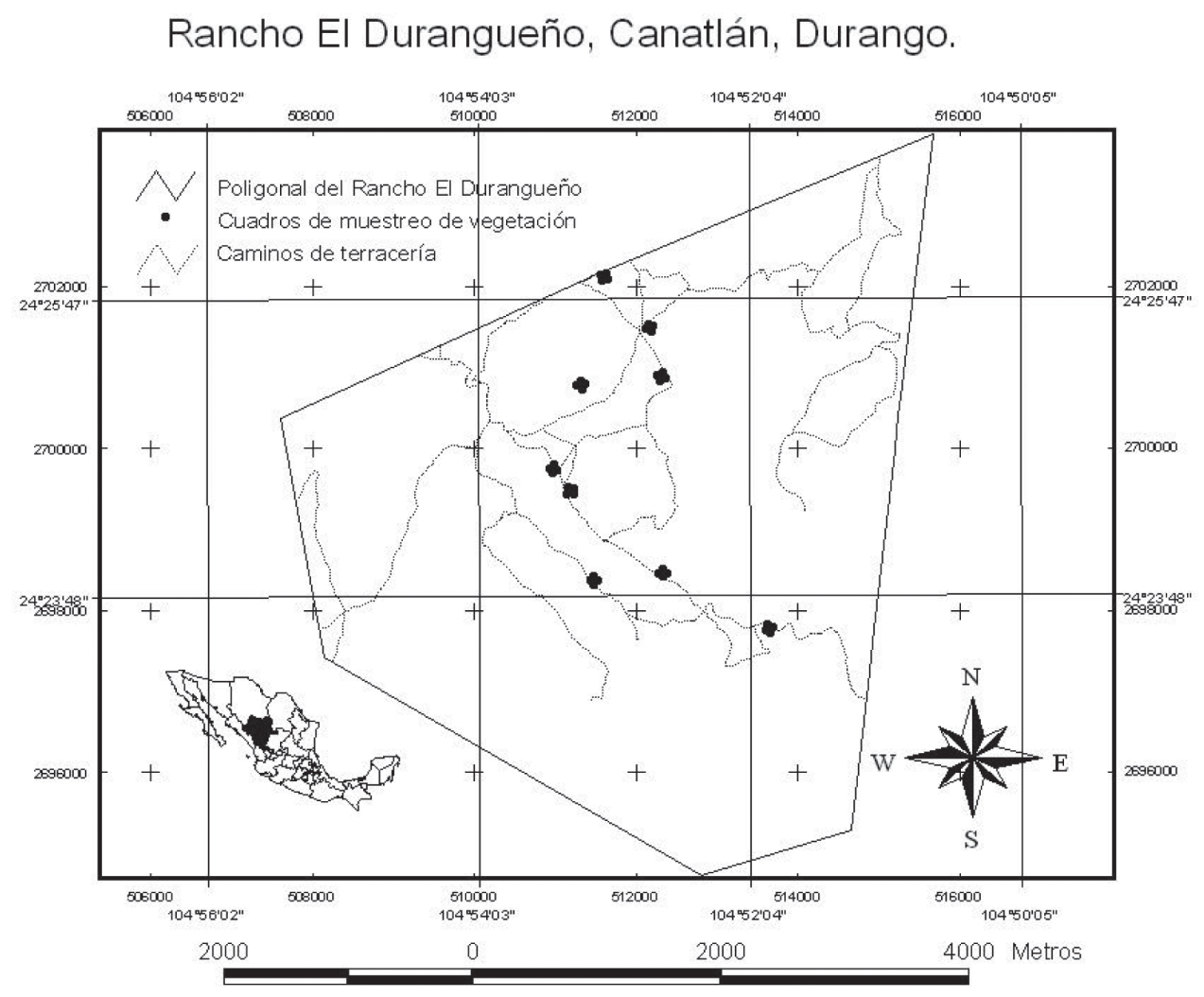

Figura 1. Ubicación del rancho El Durangueño, municipio de Canatlán, Durango; se indica la distribución de las parcelas de muestreo de la vegetación.

Cuadro 1. Ubicación y características geográficas de los sitios de muestreo en el rancho El Durangueño, municipio de Canatlán, Durango

\begin{tabular}{|c|c|c|c|c|c|}
\hline \multirow{2}{*}{$\begin{array}{l}\text { Sitio } \\
\text { PAS } 1\end{array}$} & \multicolumn{2}{|c|}{ Coordenadas geográficas } & \multirow{2}{*}{$\begin{array}{c}\text { Altitud (m smn) } \\
2456\end{array}$} & \multirow{2}{*}{$\begin{array}{c}\text { Pendiente (grados) } \\
0.74\end{array}$} & \multirow{2}{*}{$\begin{array}{r}\text { Orientación (grados } N) \\
60.95\end{array}$} \\
\hline & $104^{\circ} 53^{\prime} 18^{\prime \prime} \mathrm{O}$ & $24^{\circ} 25^{\prime} 18.228^{\prime \prime} \mathrm{N}$ & & & \\
\hline PAS 2 & $104^{\circ} 52^{\prime} 48^{\prime \prime O}$ & $24^{\circ} 25^{\prime} 41.195^{\prime \prime} \mathrm{N}$ & 2487 & 9.12 & 245.63 \\
\hline PAS 3 & $104^{\circ} 52^{\prime} 43^{\prime \prime} \mathrm{O}$ & $24^{\circ} 25^{\prime} 21.539^{\prime \prime} \mathrm{N}$ & 2450 & 4.43 & 159.23 \\
\hline BQP 1 & $104^{\circ} 53^{\prime} 23^{\prime \prime} \mathrm{O}$ & $24^{\circ} 24^{\prime} 36.000^{\prime \prime} \mathrm{N}$ & 2515 & 2.35 & 322.43 \\
\hline BQP 2 & $104^{\circ} 52^{\prime} 42^{\prime \prime} \mathrm{O}$ & $24^{\circ} 24^{\prime} 02.988^{\prime \prime} \mathrm{N}$ & 2554 & 0.68 & 341.57 \\
\hline BQP 3 & $104^{\circ} 53^{\prime} 13^{\prime \prime} \mathrm{O}$ & $24^{\circ} 26^{\prime} 02.472^{\prime \prime} \mathrm{N}$ & 2486 & 3.89 & 159.57 \\
\hline BPQ 1 & $104^{\circ} 53^{\prime} 30^{\prime \prime} \mathrm{O}$ & $24^{\circ} 24^{\prime} 44.640^{\prime \prime} \mathrm{N}$ & 2496 & 4.85 & 312.61 \\
\hline BPQ 2 & $104^{\circ} 51^{\prime} 56^{\prime \prime} \mathrm{O}$ & $24^{\circ} 23^{\prime} 40.740^{\prime \prime} \mathrm{N}$ & 2513 & 3.68 & 150.95 \\
\hline BPQ 3 & $104^{\circ} 52^{\prime} 57^{\prime \prime O}$ & $24^{\circ} 23^{\prime} 18.096 ” \mathrm{~N}$ & 2501 & 6.07 & 89.33 \\
\hline
\end{tabular}

PAS, pastizal; BQP, bosque de encino-pino; BPQ, bosque de pino-encino. 
un incendio de gran magnitud en 1997 (M.A. Osio, com. pers.).

Muestreo de campo. Se establecieron áreas generales de muestreo con base en fotografías aéreas a escala 1:20 000, considerando los rodales determinados en el plan de manejo forestal vigente (Asesoría y Servicios en Forestería, 2001). Se realizaron recorridos en campo en esas áreas y con base en la composición florística y las plantas dominantes se seleccionaron los sitios de muestreo. Se generó un mapa de localizaciones utilizando un sistema de información geográfica (ESRI, 1999) a partir de cartografía temática, un modelo digital de terreno (INEGI, 2000) y verificaciones en campo (Fig. 1). Las áreas de muestreo se describieron de acuerdo con algunas características físicas (altitud, pendiente y orientación) obtenidas a partir del modelo digital de terreno (INEGI, 2000), escala 1:250 000, con celdillas de $100 \times 100 \mathrm{~m}$ calculadas a partir de algoritmos utilizados en ARCVIEW Ver 3.2. mediante la proyección UTM zona 13 norte y el uso de un GPS.

Los sitios seleccionados correspondieron a 3 áreas de bosque de encino-pino, 3 de pino-encino y 3 de pastizal. Cada sitio fue de 0.49 ha $(70 \times 70 \mathrm{~m})$ con separaciones de 0.73 a $3.87 \mathrm{~km}$, para lo cual se consideró la ubicación de rodales (parches homogéneos estructuralmente) y la definición de unidades fisonómico-florísticas de la vegetación. Los puntos de muestreo se preseleccionaron al azar a partir de los 49 sitios de cada parcela (separados $10 \times 10 \mathrm{~m}$ ) y el número de puntos se determinó mediante la curva de acumulación de especies (Brower y Zar, 1989). En el Cuadro 1 se muestran algunas características físicas de los sitios; los intervalos de altitud variaron de 2450 a $2554 \mathrm{~m}$ snm, la pendiente de 0.68 a $9.12^{\circ}$ y la orientación de las laderas con respecto al norte fue de 60.95 a $341.57^{\circ}$ (Cuadro 1). La información de campo se caracterizó de acuerdo con 3 estratos florísticos (Brower y Zar, 1989; Krebs, 1989): alto (árboles con altura mayor de $3 \mathrm{~m}$ ), medio (plantas leñosas inferiores, árboles y arbustos menores de 3 m) y bajo (hierbas, pastos y arbustos pequeños no leñosos).

Para los estratos alto y medio se utilizó la técnica de cuadrantes centrados en un punto (Mueller Dombois y Ellenberg, 1974; Brower y Zar, 1989; Krebs, 1989). Es una modificación al método del vecino más cercano y uno de los métodos de distancia que con más frecuencia se emplean para muestrear comunidades vegetales, en particular bosques, ya que proporciona una estimación práctica y útil de la estructura. Se usa para estimar frecuencia, densidad y área basal de las especies a partir de la distancia media de 4 individuos cercanos a un punto central. No requiere la delimitación de áreas, siendo menos costoso en términos de tiempo y dificultad cuando se desean calcular densidades arbóreas en zonas de topografía accidentada, es útil, a su vez, para comunidades donde las plantas se encuentran relativamente espaciadas, como es el caso en este estudio.

Las medidas consideradas fueron distancia entre el punto central y las plantas más cercanas de acuerdo con el diseño de muestreo, altura y cobertura de las mismas. Las especies de hierbas y pastos se cuantificaron en cuadrantes de $1 \mathrm{~m}^{2}, 10$ en cada sitio de monitoreo, seleccionados al azar de las 9 áreas.

Se identificaron las plantas en los diferentes estratos, considerando fecha, localidad, sitio, punto de muestreo, especie, distancia, cobertura, diámetro a la altura del pecho (DAP) y altura. Se elaboró un pequeño manual de referencia con material fotográfico mediante observaciones y colectas de plantas en sitios aledaños a los del muestreo. El material recolectado se herborizó e identificó por taxónomos expertos del herbario CIIDIR (Centro Interdisciplinario de Investigación para el Desarrollo Integral Regional, Durango) del Instituto Politécnico Nacional.

Las especies se clasificaron por familias y de acuerdo con su endemismo y situación de riesgo (SEMARNAT, 2002; IUCN, 2007) y se destacaron las indicadoras de perturbación. La distribución de las especies se obtuvo a partir de su presencia o ausencia en cada uno de los sitios, considerando los 3 estratos.

Análisis de información. Se describieron las características de la vegetación de cada uno de los sitios, estimando la cobertura relativa y la frecuencia relativa, mediante fórmulas convencionales (Mueller-Dombois y Ellenberg, 1974; Brower y Zar, 1989; Krebs, 1989; Mitchell, 2007). Se midió el DAP y la altura de los diferentes estratos. Se estimó la densidad (absoluta y relativa) por especie utilizando la fórmula propuesta por Mitchell (2007), para reducir la desviación que ocurre cuando se usa la fórmula de Cottam y Curtis (1956) y los intervalos de confianza.

La riqueza de especies se calculó por medio del conteo de las especies de plantas registradas y la diversidad, mediante el recíproco del índice de Simpson $(\mathrm{D}=[\Sigma$ $\left.(\mathrm{ni} / \mathrm{N})^{2}\right]$, donde $\mathrm{ni}=$ abundancia de la especie $i, \mathrm{~N}=$ número total de individuos de todas las especies), la equidad (1/D) y la dominancia (1-D, intervalo de 0 a 1) (Magurran, 1988, 2004; McAleece, 1997; Hammer et al., 2005). Para detectar las diferencias significativas en los parámetros entre los sitios se emplearon pruebas de ANOVA de 1 vía (Hammer et al., 2005). Se realizó un análisis de agrupamiento entre los sitios de muestreo de acuerdo con el valor de importancia de las especies de árboles y arbustos leñosos, empleando la medida de similitud de Bray Curtis y el método de agrupación de un solo enlace (linaje simple) o del vecino más cercano (Mueller-Dombois y Ellenberg, 1974; Biodiversity Pro ver. 2.0 McAleece, 1997; Past ver. 1.3 Hammer et al., 2005). 


\section{Resultados}

Se registraron 74 especies de plantas pertenecientes a 21 familias, predominando Asteraceae, Fagaceae, Pinaceae y Poaceae (Apéndice 1). Los pastizales se ubicaron en mesas amplias o con lomeríos suaves en la zona norte del área de estudio (10\%), entre los 2496 y $2520 \mathrm{~m}$ snm, en los que se registraron 19 especies de pastos. En estos sitios se observaron pocos árboles, pero el encinillo (Quercus striatula) y un pino (Pinus chihuahuana) fueron los componentes dominantes en abundancia; otros encinos fueron escasos (PAS 1 y 3) y sólo en un pastizal se presentaron 3 especies de pino (PAS 2). Los bosques de encino-pino son la vegetación dominante en el predio (64\%), principalmente en las planicies o sitios con escasa pendiente aledañas a laderas poco pronunciadas que incluyen 7 especies de encinos, además de $P$. chihuahuana (Cuadro 2), donde uno de los sitios (BQP 2) se caracterizó por la mayor riqueza de plantas arbóreas (6 especies de encino y 3 de pino), con madroño (Arbutus spp.) y manzanita (Arctostaphylos pungens); los otros 2 (BQP 1 y BQP 2) tuvieron hasta 5 especies por sitio en el estrato alto (encinos y pinos) y matorrales de manzanita y de encinillo. Estos bosques se caracterizaron por presentar incidencia frecuente de vientos y escasa materia orgánica acumulada.

Los bosques de pino-encino cubren el 11.6\% del área, con 3 especies de pinos con densidades medias a altas $(P$. cembroides, $P$. cooperi y $P$. chihuahuana, Cuadro 2), 1 especie de encino dominante por sitio en el estrato alto, y matorral de madroño, encinillo y manzanita en el estrato medio. También presentaron gran riqueza de pastos $\mathrm{y}$ diversas especies de herbáceas, que sólo se encontraron en estas áreas, pertenecientes a los géneros Cheilanthes, Dalea, Eryngium, Indigofera, Iostephane, Mandevilla, Notholaena, Psacalium, Stevia y Tagetes. Los encinos representativos fueron $Q$. arizonica y $Q$. durifolia.

Los sitios pueden describirse también por la presencia de las especies fisonómicamente dominantes o con altos valores de importancia (Apéndices 1 y 2). En los pastizales dominaron principalmente $P$. chihuahuana, con la adición de $P$. engelmannii en uno de los sitios; en su estrato medio todos los sitios presentaron Q. striatula. En los bosques de encino-pino hubo variabilidad de las especies importantes; en un sitio, los encinos $Q$. arizonica y $Q$. durifolia; en otro, se sumó un pino (P. chihuahuana) y en un tercer sitio estuvo repartida la importancia de 3 especies con valores similares ( $Q$. arizonica, $Q$. durifolia y $Q$. eduardii). Los manzanillares (Arctostaphylos pungens) predominaron en el estrato medio en todos los lugares. Los pinares predominaron (Apéndice 2) en los estratos alto y medio; las especies importantes fueron distintas en cada uno de los sitios (P. chihuahuana y $Q$. striatula; $P$. cembroides y Arbutus arizonica; $P$. cooperi y $Q$. striatula).

En los muestreos se encontraron 16 especies de árboles $(21.6 \%), 5$ de arbustos (6.8\%) y 53 de hierbas y pastos (71.6\%, Cuadro 3) y 6 endémicas de la SMO: Iostephane madrensis, Muhlenbergia flaviseta, P. cooperi, Q. durifolia, Q. striatula, y Psacalium cronquistiorum; esta última, endémica del estado de Durango. Asimismo, se registraron 12 especies endémicas de México: Arbutus tessellata, Eryngium beecheyanum, Festuca tolucensis, Karinia mexicana, Lonicera pilosa, Muhlenbergia pubescens, Perymenium mendezii, Psacalium sinuatum, Q. conzattii, Q. eduardii, Pinus leiophylla y Roldana sessilifolia (Turner y Nesom, 1998; Herrera, 2001).

En la Lista roja de la IUCN (2010) están incluidas 7 especies en la categoría de bajo riesgo, porque no existen datos suficientes sobre su abundancia y por su distribución restringida (sólo se encuentran en las altas montañas): $Q$. depressipes, $Q$. conzattii, $P$. cembroides, $P$. engelmannii, $P$. leiophylla, A. xalapensis y Juniperus deppeana. Por otra parte, se registraron 2 especies indicadoras de perturbación (Arbutus arizonica y Aristida schiedeana) y 2 favorecidas por los incendios y/o constantes vientos (Q. striatula y $A$. pungens).

Las plantas con distribución amplia en cada uno de los estratos (mayor frecuencia y presencia en los sitios muestreados, Apéndice 1) fueron: P. chihuahuana, $Q$. durifolia y $Q$. arizonica en el estrato alto; $Q$. striatula y Arctostaphylos pungens en el medio y Muhlenbergia dubia, M. rigida, M. flaviseta y Heteropogon contortus (todas Poaceae), en el bajo, además de otras especies de hierbas, como Chaptalia runcinata, Karinia mexicana, Laennecia sp., Perymenium aff. mendezii, Stevia aff. ovata y Viguiera sp.

En el estrato alto se registraron 16 especies de árboles, generalmente bajos, de 3.8 a $6.9 \mathrm{~m}$, con algunos individuos hasta de $12 \mathrm{~m}$. Para esta forma de crecimiento el DAP presentó valores menores de $10 \mathrm{~cm}$, tanto en un pastizal (PAS 3), como en un bosque de encino-pino (BQP 2) y en 2 bosques de pino-encino (BPQ 2 y BPQ 3), mientras que en el resto de los sitios los valores fluctuaron de 14 a $45 \mathrm{~cm}$. Un bosque secundario de encino-pino presentó una alta densidad de árboles bajos (BQP 2), así como un bosque de pino-encino que presentó altas densidades de plantas (BPQ 2, Cuadro 4). El estrato medio se caracterizó por presentar 5 especies de plantas con alturas generalmente menores de 1 metro. La densidad de arbustos fue alta en 2 pastizales (17 $202 \mathrm{ind} / \mathrm{ha}$ en el PAS 1 y $8042 \mathrm{ind} /$ ha en PAS 3) y en 2 bosques mixtos (4 229 ind/ha en BQP 1 y 12,559 ind/ha en BPQ 3, Cuadro 4). En el estrato bajo, el porcentaje de poáceas varió de 18.1 a 70\%, las herbáceas desde 2.6 hasta $32.8 \%$ y los arbustos hasta $33.3 \%$, con alturas bajas $(17.5$ 
Cuadro 2. Estructura de la comunidad de árboles y arbustos leñosos de los sitios de muestreo en el rancho El Durangueño, municipio de Canatlán, Durango. Los valores máximos se muestran en negritas

\begin{tabular}{ccccc}
\hline Sitios & $R E$ & $1-D$ & $D$ & $1 / D$ \\
\hline PAS 1 & 2 & 0.50 & 0.5 & 2 \\
PAS 2 & 7 & 0.72 & 0.28 & 3.6 \\
PAS 3 & 4 & 0.67 & 0.33 & 3 \\
BQP 1 & & 0.78 & 4.5 \\
BQP 2 & 6 & 0.79 & 0.21 & 4.8 \\
BQP 3 & 11 & 0.83 & 0.17 & $\mathbf{5 . 9}$ \\
BPQ 1 & 8 & 0.72 & 0.28 & 3.6 \\
BPQ 2 & 7 & 0.62 & 0.38 & 2.6 \\
BPQ 3 & 5 & 0.74 & 0.27 & 3.8 \\
F, gl = 8 & 7 & 3.76 & 3.76 & 7.9 \\
P & 2.57 & 0.09 & 0.09 & 0.02 \\
\hline
\end{tabular}

PAS, pastizal; $\mathrm{BQP}$, bosque de encino-pino y $\mathrm{BPQ}$, bosque de pino-encino. $R E$, riqueza de especies; $D$, índice de Simpson; $1-D$, dominancia; $1 / D$, equidad. $\mathrm{F}$, prueba $\mathrm{F}$ obtenida a partir de los ANOVA de una vía; $\mathrm{P}$, probabilidad, gl, grados de libertad.

Cuadro 3. Riqueza de especies en los diferentes sitios y por estrato en el rancho El Durangueño, municipio de Canatlán, Durango

\begin{tabular}{|c|c|c|c|c|c|c|c|c|c|c|}
\hline & \multicolumn{3}{|c|}{ Pastizal } & \multicolumn{3}{|c|}{$\begin{array}{l}\text { Bosque de } \\
\text { encino-pino }\end{array}$} & \multicolumn{3}{|c|}{$\begin{array}{l}\text { Bosque de } \\
\text { pino-encino }\end{array}$} & \multirow[t]{2}{*}{ Total (\%) } \\
\hline & 1 & 2 & 3 & 1 & 2 & 3 & 1 & 2 & 3 & \\
\hline Estrato alto & 1 & 5 & 3 & 4 & 8 & 4 & 4 & 4 & 5 & $16(21.6)$ \\
\hline Estrato medio & 1 & 2 & 1 & 2 & 6 & 5 & 3 & 1 & 3 & $5(6.8)$ \\
\hline Estrato bajo & 11 & 19 & 12 & 13 & 17 & 8 & 15 & 15 & 13 & $53(71.6)$ \\
\hline Total & 13 & 26 & 16 & 19 & 31 & 17 & 22 & 20 & 21 & $74(100)$ \\
\hline
\end{tabular}




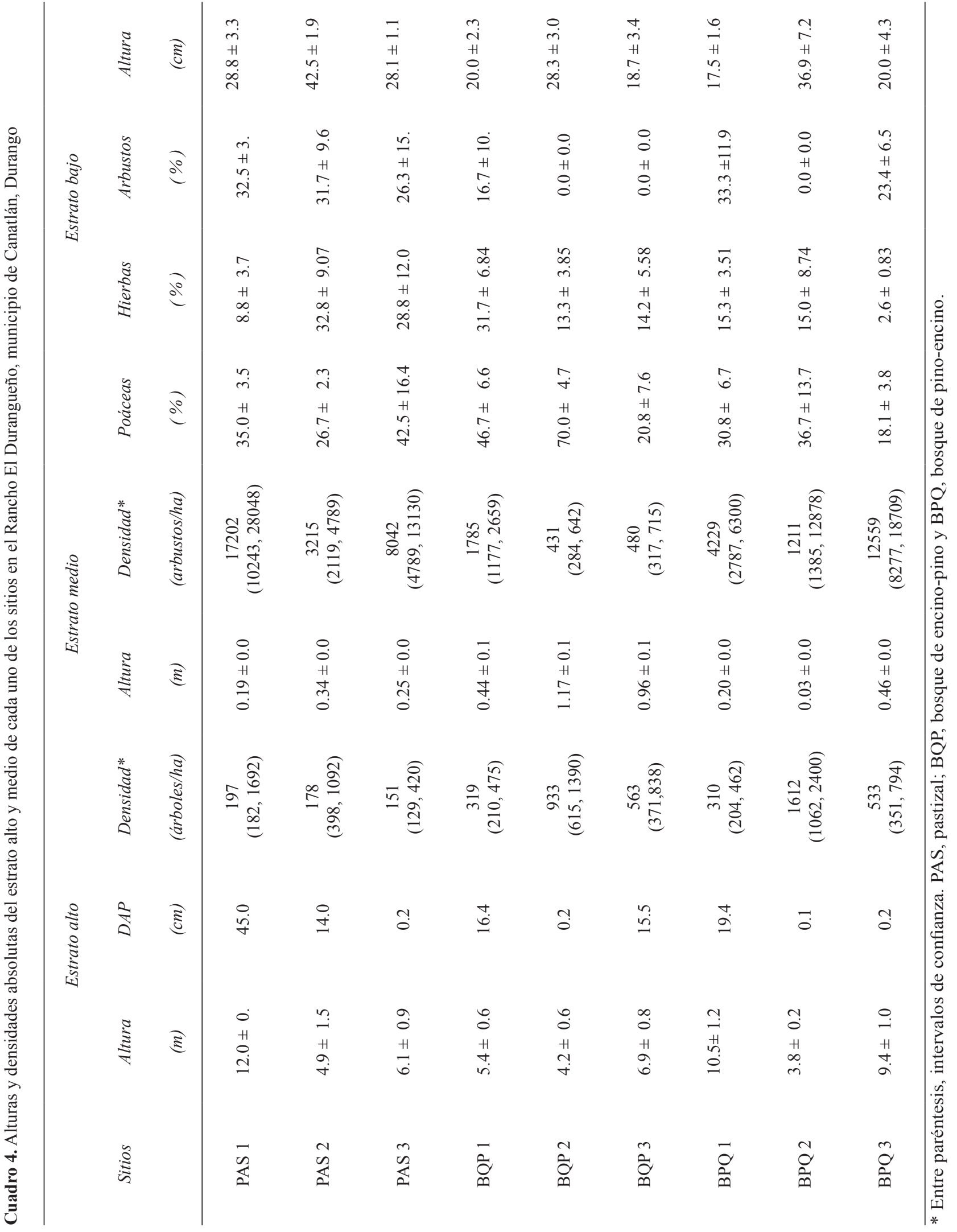


a $42.5 \mathrm{~cm}$, Cuadro 4), presentando 53 especies, 19 de éstas pertenecientes a Poaceae (Anexo 1). La riqueza de especies, la diversidad y la dominancia de los estratos alto y medio fue similar entre los sitios (Cuadro 2), encontrándose hasta 11 especies con valores de dominancia de 0.5 a 0.83 y de 0.17 a 0.5 de diversidad; sólo se encontró diferencia significativa en la equidad de los bosques de encino-pino (intervalo de 4.5 a 5.9) con respecto a los sitios restantes $(\mathrm{F}=7.9, \mathrm{P}=0.02$, gl. $8, \mathrm{Q}=5.33, \mathrm{P}=0.02$ ).

Finalmente, el análisis de agrupamiento de los valores de importancia de las especies de plantas se consideró al $50 \%$. Este porcentaje se seleccionó de acuerdo con los mayores valores de similitud que los pastizales presentaron entre ellos y con lo que se observó en campo. El análisis mostró la formación de 6 grupos (Fig. 2), quedando en uno de estos los pastizales, 2 bosques de encino-pino en

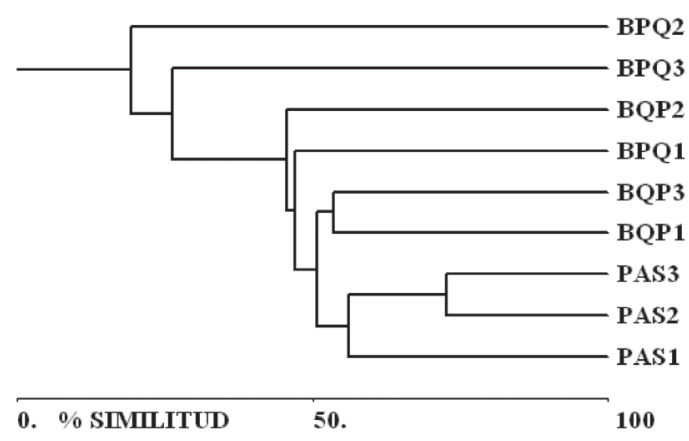

Figura 2. Dendrograma derivado del análisis de agrupamientos de los datos de valor de importancia de especies de los estratos alto y medio, utilizando la medida de similitud de Bray-Curtis y el algoritmo de linaje simple.

otro (BQP1 y BQP 3), y los sitios restantes independientes entre sí.

\section{Discusión}

El Rancho El Durangueño presenta mosaicos de vegetación en áreas cercanas, generalmente menores de 1 hectárea y gran variabilidad en cuanto a la exposición de las laderas, características comunes en la Sierra Madre Occidental (Cuadro 1, Challenger, 1998), no obstante que los intervalos de altitud y pendiente fueron reducidos.

En cuanto a la flora, se encontraron especies que ya habían sido registradas en algunos sitios de la SMO en Durango y coinciden las familias dominantes (González et al., 1993, 2007; Márquez y González, 1998). Sin embargo, hubo diferencias en cuanto a las especies dominantes en estos sitios con respecto a los antes mencionados, que corresponden a especies de bosques templados más secos (Q. arizonica, Q. durifolia, Q. striatula, P. chihuahuana, entre otras), más afines a las zonas de transición de la vegetación de la SMO.

Los sitios muestreados fueron representativos de la vegetación dominante del rancho, permitiendo clasificarlos como bosques de encino-pino, bosques de pino-encino y pastizales naturales. En 2 de los sitios estudiados (BPQ1 y BPQ3) se presentan comunidades típicas del macizo montañoso de la $\mathrm{SMO}$, mientras que todos los restantes corresponden, por su estructura y composición, a bosque bajo abierto (González et al., 2007), que muestran buen estado de conservación, donde se registraron varias especies endémicas de esta cordillera, del estado de Durango y de México (Rzedowski, 1978, 1998), representativas tanto de los bosques templados semisecos como de los templados húmedos, donde destaca $P$. cooperi. Algunas especies de pinos y de encinos están incluidas en la Lista roja de la IUCN y se consideran vulnerables $(P$. cembroides, $P$. engelmannii, $Q$. depressipes y $Q$. conzattii), ya que su distribución se restringe a los bosques de la SMO en México y al sur de los Estados Unidos de América (Rzedowski, 1991; Styles, 1998; NatureServe, 2007).

Se registraron escasas especies indicadoras de perturbaciones humanas, cuya presencia generalmente se asoció con la vegetación secundaria. Estas especies llegan a ser de gran importancia ecológica en estos bosques, como es el caso de Q. striatula y Arctostaphylos pungens, entre otras, cuyos frutos son el alimento preferido de muchas especies de fauna silvestre (Martínez, 1996; Morales et al., 1997; Garza et al., 1998; Garza, 2005). La presencia de madroños (Arbutus spp.) es un indicador de sitios abiertos y expuestos a insolación. El encinillo se presenta como dominante en algunos sitios, ya que su hábito rizomatoso lo hace resistente al fuego y a otras perturbaciones (González et al., 1993). Los suelos donde se presentaron fueron someros, algo pedregosos y con escaso afloramiento de roca madre.

Las especies dominantes y de amplia distribución correspondieron más a bosques de la vertiente oriental de la Sierra Madre y a los bosques secos expuestos a vientos en la zona de transición o ecotonal de chaparrales propios del altiplano o de valles entre la SMO. No obstante, en algunos sitios se detectaron especies arbóreas asociadas a cierto grado de humedad, como Q. candicans (Rzedowski, 1978). Las hierbas correspondieron tanto a los bosques templados secos como a bosques semihúmedos; se encontraron especies indicadoras de zonas inundables como Karinia mexicana. La mayor parte de las especies de pastos presentes fueron típicas de los pastizales naturales 
en ecotonía con bosques abiertos, mientras que unas pocas (e.g. Muhlenbergia emersleyi, M. flaviseta o M. pubescens) corresponden a elementos de claros en bosques templados.

Las características estructurales indicaron buenas coberturas, presencia de árboles no muy altos y diámetros (DAP) variables, pero con densidades similares a otros sitios de la SMO (González et al., 1993). Posiblemente el tamaño medio del arbolado está relacionado con la existencia de suelos someros en la zona, de aproximadamente $30 \mathrm{~cm}$ de profundidad, lo cual no permite el desarrollo de árboles de gran tamaño (M.A. Osio, com. pers.). La existencia de encinares de tamaño mediano $(Q$. durifolia) y bajo corresponde con lo que registra Maysilles (1959). Están incluidos dentro de una franja estrecha que constituye la zona de transición entre el pastizal y el bosque.

El sotobosque es rico en especies de hierbas y pastos, principalmente de las familias Asteraceae y Poaceae y corresponde con lo registrado para algunos bosques de zonas templadas de México, con representantes de los géneros Eryngium, Festuca, Muhlenbergia, Penstemon, Salvia, Senecio, Stevia, Stipa y Tagetes (Rzedowski, 1998; Ramamoorthy y Elliott, 1998; Challenger, 1998). Por lo anterior, la heterogeneidad de los sitios permite la presencia de mosaicos de vegetación en distancias relativamente cercanas.

La presencia de matorral de encinillo, especie de amplia distribución en El Durangueño puede ser indicador de perturbaciones recientes de baja intensidad (Osio et al., 2007) derivadas de las actividades forestales, ya que en fechas cercanas se han realizado aprovechamientos forestales a baja escala (programa de manejo autorizado desde 2001), o bien, debidas a la sequía, pues se tienen registros de sequía severa entre 1982 y 2000, o probablemente a los incendios ocurridos dentro del predio en 1965 - hubo uno de gran magnitud en 1997 en zonas aledañas-, causas que pudieron afectar pero no dañar la estructura del suelo y favorecieron la presencia de este encino. Lo anterior se deduce a partir de la información que se tiene de la especie, como resistente al fuego y de su dominancia indicadora de disturbios (González et al., 1996). Además es sabido que este arbusto se establece después del aprovechamiento forestal, de incendios, o donde ha habido una perturbación ligera, pero no donde se ha destruido la estructura del suelo (Mancinas, 2002).

La composición de los pastizales corresponde a zacates amacollados, principalmente de los géneros Muhlenbergia, Heteropogon y Aristida que poseen diversidad media y presentan buenas coberturas, algunas de estas características se llegan a presentar en zonas de ecotono entre pastizal de los valles y bosques de encino, al pie de monte oriental de la sierra y en pequeñas sierras aisladas (González et al., 2007). Por lo tanto, la presencia de algunos de esos componentes florísticos y de 1 o 2 especies de árboles en estos sitios indican su carácter transicional entre los pastizales propiamente dichos y los bosques templados.

El análisis de los valores de importancia de las especies de los estratos alto y medio mostró una tendencia hacia una baja similitud entre los sitios (menores de 50\%, intervalo de 1.5 a 45.7\%), exceptuando los 3 pastizales, en donde este grupo se separó de los lugares restantes, presentando similitudes de alrededor del 56 al 73\% entre cada pastizal (Fig. 2). Se hizo evidente que 2 bosques de pino-encino se separaron con respecto a las demás áreas, por su distinta composición y los valores de importancia de las especies: una zona conservada muy arbolada con dominancia de $P$. cembroides y $Q$. arizonica (BPQ2) y otro bosque de pino-encino (BPQ3) dominado por árboles de $P$. cooperi. Los bosques de encino-pino presentaron similitudes entre si, siendo uno de los sitios distinto en cuanto a mayor composición, riqueza y diversidad de especies y correspondiendo a un bosque que fue explotado forestalmente hace un par de décadas, ya que la vegetación actual de ese sitio es secundaria.

Los valores de diversidad fueron similares entre todos los tipos de vegetación (Cuadro 2) y la equidad fue mayor en los bosques mixtos de encino-pino que en los otros sitios, mientras que en ambos parámetros los valores fueron similares a lo registrado para otras áreas de la SMO. Por ejemplo, en los bosques de encino-pino y pino-encino de la Reserva de la Biosfera La Michilía $(\mathrm{D}=0.13$ a 0.56 y 0.26 a $0.35,1-\mathrm{D}=0.4$ a 0.85 y 0.65 a 0.81 , respectivamente; González et al., 1993). Comparado con los encinares de los bosques templados de Santa Rosa, Guanajuato, se observó cierta similitud en cuanto a la riqueza total de especies (riqueza de especies de 17 a 29; Martínez-Cruz et al., 2009), sitio que se ha registrado con influencia de actividad humana, alta riqueza de especies de encinos y presencia de especies tolerantes a la incidencia de incendios, como lo son en este estudio la manzanita (Márquez et al., 1999) y el encinillo (Mancinas, 2002).

La presencia de diferentes comunidades vegetales a manera de mosaicos a corta distancia y su composición específica, probablemente son resultado de cambios históricos y ecológicos, donde se han mezclado especies tanto de la región neártica como de la neotropical, siendo éste un sitio importante para la diversificación y la existencia de endemismos.

\section{Agradecimientos}

Este estudio forma parte del proyecto "Biodiversidad 
del rancho El Durangueño, Canatlán, Durango", financiado por la CONAFOR (Expediente III-10-CABSA-0341) y coordinado por Alfredo Garza Herrera (Centro de Ecología Regional, A.C.-CERAC). Se agradece al Instituto de Ecología, A.C. (INECOL-DGO), al Centro de Ecología Regional, A.C, al CIIDIR-IPN Durango, a la Facultad de Ciencias de la UNAM y al Posgrado en Ciencias Biológicas del Instituto de Biología de la UNAM, por otorgar las facilidades y/o el apoyo para desarrollar este estudio. En especial se agradece a la doctora Yolanda Herrera Arrieta del herbario CIIDIR; asímismo, a Alberto Arvizu, Sergio Gutiérrez, Miguel Osio, Alfredo Sánchez, Gerardo Daniel de León, Cynthia P. Sánchez y Francisco Sánchez, por su apoyo en las actividades de campo. Se agradece profundamente a los señores Rodrigo y Alonso Ayala Grimaud, propietarios del rancho El Durangueño y al señor Issac Rafael Velásquez, por el apoyo y las facilidades para el desarrollo de este estudio y a los árbitros anónimos que revisaron y con sus sugerencias enriquecieron este manuscrito.

\section{Literatura citada}

Arriaga, L., J. M. Espinoza, C. Aguilar, E. Martínez, L. Gómez y E. Loa (coords.). 2000. Regiones terrestres prioritarias de México. Comisión Nacional para el Conocimiento y Uso de la Biodiversidad, México, D.F. 609 p. y mapa.

Arriaga, L., V. Aguilar y J. Alcocer. 2002. Aguas continentales y diversidad biológica de México. Comisión Nacional para el Conocimiento y Uso de la Biodiversidad. México, D.F. 327 p. y mapa.

Asesoría y Servicios en Forestería. 2001. Programa de manejo forestal del predio privado "El Durangueño”, Mpio. Canatlán, Dgo. Informe técnico. Durango, Durango.

McAleece, N. 1997. Biodiversity Professional Beta., ver 2.0. The Natural History Museum and The Scotish Association for Marine Science, Oban.

Brower, E. J., H. J. Zar y N. C. Von Ende 1989. Field and laboratory methods for general ecology, tercera edición. Wm. C. Brown, Dubuque, Iowa. 237 p.

Bye, R. 1995. Prominence of the western Sierra Madre Occidental in the biological diversity of Mexico. In Biodiversity and management of the Madrean Archipelago, L. DeBano, G. Gottfnied, L. Hamre, C. Edminser, P. Folliott y A. Ortega (eds.). USDA Forest Service General Technical Report. RMGTR-264. p. 19-27.

Challenger, A. 1998. Utilización y conservación de los ecosistemas terrestres de México: pasado, presente y futuro. Comisión Nacional para el Conocimiento y Uso de la Biodiversidad/Instituto de Biología, UNAM/Agrupación Sierra Madre, México, D.F. 847 p.
Cottam, G. y J. T. Curtis. 1956. The use of distance measures in phytosociological sampling. Ecology 37:451-460.

DETENAL (Departamento de Estudios del Territorio Nacional) 1972. Modificaciones al Sistema de Unidades FAOUNESCO 1968, DETENAL, México, D.F.

ESRI (Environmental Systems Research Institute) 1999. ArcView 3.2 GIS. Environmental Systems Research Institute, Nueva York, $340 \mathrm{p}$.

FAO-UNESCO. 1974. Soil map of the world (1:5,000,000), vol. 1. Legend. UNESCO, Paris. 59 p.

García, E. 2004. Modificaciones al sistema de clasificación climática de Köppen, para adaptarlo a las condiciones de la República Mexicana, $5^{\text {a }}$ edición, Serie Libros Núm. 6. Instituto de Geografía, UNAM, México, D.F. 90 p.

Garza, A. 2005. Ecología del cócono silvestre en Durango, México (Aves: Meleagris gallopavo mexicana). Tesis de maestría. Facultad de Ciencias, Universidad Nacional Autónoma de México, México, D.F. 91 p.

Garza, A., O. V. Martínez y E. E. Aragón. 1998. Microhistología de las especies vegetales comunes en la dieta de los herbívoros silvestres de la Sierra Madre Occidental. Ubamari 45:48-72.

Garza, A., E. E. Aragón, E. Rivera, G. D. De León, C. Sánchez, R. G. González, F. A. Sánchez, C. Domínguez, A. Arvizu, S. R. Gutiérrez, M. A. Osio y A. Chávez. 2005. Biodiversidad del Rancho "El Durangueño", Canatlán, Durango. Informe técnico (Expediente III-10-CABSA-0341), PRODEFOR 2004. Comisión Nacional Forestal/Gobierno del Estado de Durango / Instituto de Ecología, Durango, Durango. 88 p.

Gentry, H.S. 1957. Los pastizales de Durango. Estudio ecológico, fisiográfico y florístico. Instituto Mexicano de Recursos Naturales Renovables, México, D.F. 361 p.

González, M., S. González y Y. Herrera. 1991. Listados florísticos de México. IX. Flora de Durango. Instituto de Biología, UNAM, México, D.F. 167 p.

González, S. y M. González. 1995. Los encinos de Durango, México. Memorias. III Seminario Nacional sobre utilización de encinos, Linares, Nuevo León. p. 28-33.

González, S., M. González y A. Cortés. 1993. Vegetación de la Reserva de la Biosfera "La Michilía", Durango, México. Acta Botanica Mexicana 22:1-104.

González, S., M. González E. y M. A. Márquez L. 2007. Vegetación y ecorregiones de Durango. Plaza y Valdés / Instituto Politécnico Nacional, México, D.F. 219 p.

Gordon, A.G. 1968. Ecology of Picea chihuahuana Martínez. Ecology 49:880-896.

Hammer, O., D. A. T.HarperyP.D. Ryan. 2005.PAST-Paleontological statistics, ver. 1.34. Paleontological Museum of Oslo.

Herrera, Y. 2001. Las gramíneas de Durango. Instituto Politécnico Nacional/Comisión Nacional para el Conocimiento y Uso de la Biodiversidad, México, D.F. 478 p.

INEGI, 2000. Modelos digitales de terreno. http://mapserver. inegi.gob.mx/geografia/espanol/normatividad/mde/menu. 
$\mathrm{cfm} ? \mathrm{c}=198 ; 15$. XI.2009.

INEGI (Instituto Nacional de Estadística y Geografía). 2009. Anuario estadístico de Durango http://www.inegi.gob. $\mathrm{mx} / \mathrm{est} / \mathrm{contenidos/espanol/sistemas/sisnav/default.}$ aspx proy $=$ aee \&edi $=2008 \&$ ent $=10 ; 15 . X I .2009$.

IUCN. 2010. Red list of threatened species. www.iucnredlist.org.

Krebs, J.C. 1989. Ecological methodology. Harper Collins, Nueva York. 654 p.

Madrigal, X. 1977. Características generales de la vegetación del estado de Durango. Ciencia Forestal 2:30-58.

Magurran, A.E. 1988. Ecological diversity and its measurement. Princeton University Press, Nueva Jersey. 179 p.

Magurran, A.E. 2004. Measuring biological diversity. Blackwell, Oxford. viii $+256 \mathrm{p}$.

Mancinas, J.A. 2002. Resumen público de certificación de rancho Molinillos, S.P.R. de R.L. Certificado: SW-FM/COC-194. Informe presentado al Consejo de Manejo Forestal (Forest Stewardship Council o FSC) y de Smart Wood Program. 33 p.

Márquez, L.M. y S. González. 1998. Composición y estructura del estrato arbóreo de un bosque de pino-encino de Durango, México. Agrociencia 32:413-419.

Márquez, L.M., E. Jurado y S. González. 2006. Algunos aspectos de la biología de la manzanita (Arctostaphylos pungens HBK.) y su papel en el desplazamiento de los bosques templados por chaparrales. Ciencia Universidad Autónoma de Nuevo León 9:57-64.

Martínez, M. 1945. Las pináceas mexicanas. Anales del Instituto de Biología, Universidad Nacional Autónoma de México 16:1-345.

Martínez, O. V. 1996. Hábitos alimentarios y parásitos intestinales del guajolote silvestre en la Reserva de la Biosfera La Michilía, Durango. Tesis, Escuela Superior de Biología, Universidad Juárez del Estado de Durango, Gómez Palacio, Durango. 67 p.

Martínez-Cruz, J., O. Téllez y G. Ibarra-Manríquez. 2009. Estructura de los encinares de la Sierra de Santa Rosa, Guanajuato, México. Revista Mexicana de Biodiversidad 80: 146-156.

Maysilles, J.H. 1959. Floral relationships of the pine forests of western Durango, Mexico. Ph.D. Thesis. University of Michigan, Ann Arbor, Michigan. 165 p.

McAleece, N. 1997. Biodiversity professional beta. Versión 2.0. The Natural History Museum and the Scotish Association for Marine Science, Oban.

Mitchell, K. 2007. Quantitative analysis by the point-centered quarter method, ver. 2.5. http://people.hws.edu/mitchell/ PCQM.pdf.

Mittermeier, A.R. y C.G. Mittermeier. 1992. La importancia de la diversidad biológica de México. In México ante los retos de la biodiversidad, J. Sarukhán y R. Dirzo (comps.). Comisión Nacional para el Conocimiento y Uso de la Biodiversidad, México, D.F. p. 63-74.
Morales G., A., A. Garza y J. C. Sotomayor. 1997. Dieta del guajolote silvestre en Durango, México. Revista Chilena de Historia Natural 70:403-414.

Mueller-Dombois, D. y H. Ellenberg. 1974. Aims and methods of vegetation ecology. Wiley, Nueva York - Toronto. 547 p.

NatureServe, 2007. NatureServe explorer: An online encyclopedia of life, ver. 6.2. NatureServe, Arlington, Virginia. http:// www.natureserve.org/explorer; 8.XII.2009.

Osio, M.A., A. Garza, E. Aragón, D. de León, R. González, A. Sánchez, S. Gutiérrez y A. Arvizu. 2007. Ejecución del proyecto para la protección de la biodiversidad del predio particular "El Durangueño", Canatlán, Durango. Expediente III-10-CABSA-0341. Informe Técnico. Centro de Ecología Regional A.C. / Comisión Nacional Forestal (CONAFOR) / Consultoría en Forestería, Durango, Durango. 89 p.

Passini, M.F. 1985. Les forêst de Pinus cembroides Zucc. de la Sierra de Urica. Réserve de la Biosphére "La Michilía" (etat de Durango, Mexique). Bulletin d'Ecologie 16:161-168.

Ramamoorthy, T.P. y M. Elliott. 1998. Lamiaceae de Mexico: diversidad, distribución, endemismo y evolución. In Diversidad biológica de México: orígenes y distribución, T. P. Ramamoorthy, R. Bye, A. Lot y J. Fa. (eds.). Universidad Nacional Autónoma de México, México, D.F. p. 501-526.

Rzedowski, J. 1978. La vegetación de México. Limusa, México, D.F. $432 \mathrm{p}$.

Rzedowski, J. 1991. El endemismo en la flora fanerogámica mexicana: Una apreciación analítica preliminar. Acta Botanica Mexicana 15:47-64.

Rzedowski, J. 1998. Diversidad y orígenes de la flora fanerogámica de México. In Diversidad biológica de México: orígenes y distribución, T. P. Ramamoorthy, R. Bye, A. Lot y J. Fa. (eds.). Universidad Nacional Autónoma de México, México, D.F. p. 129-145.

Sánchez, O., E. Vega, E. Peters y O. Monrroy-Vilchis. 2003. Conservación de ecosistemas templados de montaña en México. Instituto Nacional de Ecología (INE-SEMARNAT), México, D.F.

SEMARNAT (Secretaría del Medio Ambiente yRecursos Naturales). 2002. Norma Oficial Mexicana NOM-059ECOL-2001. Protección ambiental de especies nativas de México de flora y fauna silvestre-Categorías de riesgo y especificaciones para su inclusión o cambio-Lista de especies en riesgo. Diario Oficial de la Federación 43, México, D.F.

SEMARNAT (Secretaría del Medio Ambiente yRecursos Naturales) 2009. http://www.semarnat.gob.mx/estados/ durango/temas/ Paginas/aprov_forestal.aspx; 8.XII.2009

Styles, B. T. 1998. El género Pinus: su panorama en México. In Diversidad biológica de México: orígenes y distribución, T. P. Ramamoorthy, R. Bye, A. Lot y J. Fa. (eds.). Universidad Nacional Autónoma de México. México, D.F. p. 285-408.

Turner, B. L. y G. L. Nesom. 1998. Biogeografía, diversidad y situación de peligro o amenazada de Asteraceae de México. 
In Diversidad biológica de México: orígenes y distribución, T. P. Ramamoorthy, R. Bye, A. Lot y J. Fa. (eds.). Universidad Nacional Autónoma de México. México, D.F. p. 545-561.
Valencia-Ávalos, S. 2004. Diversidad del género Quercus (Fagaceae) en México. Boletín de la Sociedad Botánica de México 75:33-53.

Apéndice 1. Presencia (1) y ausencia (0) de las 74 especies de plantas censadas en 3 tipos de vegetación en el rancho El Durangueño. El número entre paréntesis indica el número de especies por familia. 1, 2 y 3 indican cada uno de los 3 sitios por tipo de vegetación.

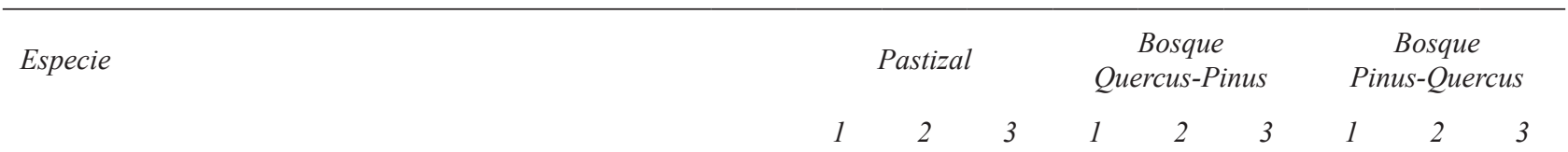

ADIANTACEAE (3)

Cheilanthes sp.1

Cheilanthes sp. 2

Notholaena sinuata (Lag. ex Sw) Kaulf.

$\begin{array}{lllllllll}0 & 0 & 0 & 0 & 0 & 0 & 0 & 1 & 0 \\ 0 & 1 & 0 & 0 & 1 & 0 & 0 & 0 & 0 \\ 0 & 0 & 0 & 0 & 0 & 0 & 0 & 1 & 0\end{array}$

AMARYLLIDACEAE (1)

Polianthes aff. nelsonii Rose

APOCYNACEAE (1)

Mandevilla foliosa Hemsl.

ASTERACEAE (15)

Chaptalia runcinata Kunth

Erigeron sp.

Iostephane madrensis (S. Watson) Strother

Laennecia sp.

Perymenium aff. mendezii DC.

Psacalium cronquistiorum B.L. Turner

P. sinuatum (Cerv.) H. Rob. et Brettell

Roldana sessilifolia (Hook et Arn.) H. Rob. et Brettell

Stevia aff. ovata Willd.

S. porphyrea McVaugh

S. serrata Cav.

Tagetes sp.

Viguiera sp.

Xanthocephalum wrightii (A. Gray) A. Gray

Xanthocephalum sp.

CAMPANULACEAE (1)

Lobelia irasuensis Planch. et Oerst.

0$$
0
$$

0

1

0

0

0

0

0

$\begin{array}{llll}0 & 0 & 0 & 0\end{array}$


Apéndice 1. Continúa.

\begin{tabular}{|c|c|c|c|c|c|c|c|c|c|}
\hline \multirow[t]{2}{*}{ Especie } & \multicolumn{3}{|c|}{ Pastizal } & \multicolumn{3}{|c|}{$\begin{array}{c}\text { Bosque } \\
\text { Quercus-Pinus }\end{array}$} & \multicolumn{3}{|c|}{$\begin{array}{c}\text { Bosque } \\
\text { Pinus-Quercus }\end{array}$} \\
\hline & 1 & 2 & 3 & 1 & 2 & 3 & 1 & 2 & 3 \\
\hline \multicolumn{10}{|l|}{ CAPRIFOLIACEAE (1) } \\
\hline Lonicera pilosa (Kunth) Willd. & 0 & 0 & 0 & 0 & 1 & 1 & 0 & 0 & 0 \\
\hline \multicolumn{10}{|l|}{ CISTACEAE (1) } \\
\hline Helianthemum glomeratum (Lag.) Lag. & 0 & 0 & 0 & 0 & 1 & 0 & 0 & 1 & 0 \\
\hline \multicolumn{10}{|l|}{ COMMELINACEAE (1) } \\
\hline Commelina sp. & 1 & 1 & 0 & 1 & 1 & 0 & 0 & 0 & 0 \\
\hline \multicolumn{10}{|l|}{ CONVOLVULACEAE (1) } \\
\hline Evolvulus rotundifolius Hallier F. & 0 & 0 & 0 & 0 & 0 & 1 & 0 & 0 & 0 \\
\hline \multicolumn{10}{|l|}{ CUPRESSACEAE (1) } \\
\hline Juniperus deppeana Steud. & 0 & 0 & 0 & 0 & 0 & 0 & 0 & 1 & 0 \\
\hline \multicolumn{10}{|l|}{ CYPERACEAE (1) } \\
\hline Karinia mexicana (Britton) Reznicek et McVaugh & 1 & 0 & 1 & 1 & 0 & 0 & 1 & 0 & 0 \\
\hline \multicolumn{10}{|l|}{ ERICACEAE (4) } \\
\hline Arbutus arizonica (A. Gray) Sarg. & 0 & 0 & 0 & 0 & 1 & 1 & 0 & 1 & 0 \\
\hline A. tessellata Sorensen & 0 & 0 & 0 & 0 & 1 & 0 & 1 & 0 & 0 \\
\hline A. xalapensis var. bicolor Kunth & 0 & 0 & 0 & 0 & 1 & 1 & 0 & 0 & 0 \\
\hline Arctostaphylos pungens Kunth & 0 & 1 & 0 & 1 & 1 & 1 & 1 & 0 & 1 \\
\hline \multicolumn{10}{|l|}{ FABACEAE (2) } \\
\hline Indigofera aff. montana Rose & 0 & 0 & 0 & 0 & 0 & 0 & 0 & 1 & 0 \\
\hline Dalea pectinata Kunth & 0 & 0 & 0 & 0 & 0 & 0 & 0 & 0 & 1 \\
\hline \multicolumn{10}{|l|}{ FAGACEAE (9) } \\
\hline Quercus aff.candicans Née & 0 & 0 & 0 & 0 & 0 & 0 & 0 & 0 & 1 \\
\hline Q. aff. depressipes Trel. & 0 & 0 & 0 & 0 & 0 & 0 & 0 & 0 & 1 \\
\hline Q. arizonica Sarg. & 0 & 1 & 0 & 1 & 1 & 1 & 0 & 1 & 0 \\
\hline Q. conzattii Trel. & 0 & 0 & 0 & 0 & 1 & 0 & 0 & 0 & 1 \\
\hline Q. durifolia Seeman & 0 & 1 & 0 & 1 & 1 & 1 & 1 & 0 & 1 \\
\hline Q. eduardii Trel. & 0 & 0 & 0 & 0 & 1 & 0 & 0 & 0 & 0 \\
\hline Q. grisea Liebm. & 0 & 0 & 0 & 0 & 0 & 1 & 0 & 0 & 0 \\
\hline Q. hartwegii Benth. & 0 & 0 & 0 & 0 & 1 & 0 & 0 & 0 & 0 \\
\hline Q. striatula Trel. & 1 & 1 & 1 & 1 & 1 & 1 & 1 & 0 & 1 \\
\hline
\end{tabular}


Apéndice 1. Continúa.

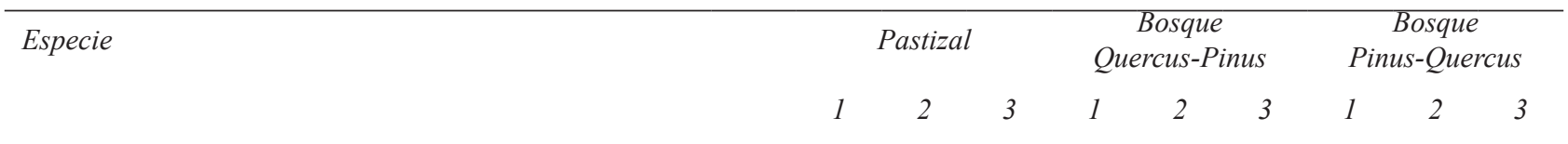

GERANIACEAE (1)

Geranium sp.

LAMIACEAE (1)

Salvia nana Kunth.

LILIACEAE (1)

Calochortus sp.

PINACEAE (6)

Pinus cembroides Zucc.

P. chihuahuana Engelm.

P. cooperi C.E. Blanco

P. cooperi var. ornelasi C.E. Blanco et Martínez

$P$. engelmannii Carrière

P. leiophylla Schiede ex Schltdl. et Cham.

$\begin{array}{lllllll}0 & 0 & 0 & 0 & 1 & 0 & 1\end{array}$

\section{POACEAE (19)}

Achnantherum eminens (Cav.) Barkworth Agrostis sp.

Aristida schiedeana Trin. et Rupr.

Aristida sp.

Blepharoneuron tricholepis (Torr.) Nash.

Festuca tolucensis Kunth

Heteropogon contortus (L.) Beauv. ex Roem et Schult.

Lycurus phleoides Kunth

Muhlenbergia dubia E. Fourn.

M. emersleyi Vasey

M. flaviseta Scribn.

M. montana (Nutt.) Hitchc.

M. pubescens (Kunth) Hitchc.

M. rigida (Kunth) Trin.

Muhlenbergia sp.1

Muhlenbergia sp.6

Piptochaetium fimbriatum (Kunth) Hitchc.

Schizachyrum sp.

Trisetum kochianum Hern. Torres

$\begin{array}{lllllllll}0 & 0 & 0 & 0 & 0 & 1 & 0 & 0 & 1 \\ 1 & 0 & 0 & 0 & 0 & 0 & 0 & 0 & 0 \\ 0 & 1 & 1 & 0 & 1 & 0 & 0 & 1 & 0 \\ 1 & 1 & 1 & 1 & 1 & 1 & 1 & 1 & 0 \\ 0 & 0 & 0 & 0 & 0 & 0 & 1 & 0 & 1 \\ 0 & 0 & 0 & 0 & 0 & 0 & 1 & 0 & 1 \\ 0 & 1 & 1 & 1 & 0 & 0 & 0 & 0 & 0 \\ 0 & 0 & 0 & 0 & 1 & 0 & 0 & 0 & 0\end{array}$

\section{SCROPHULARIACEAE (2)}

Agalinis peduncularis Pennell

Penstemon aff. apateticus Straw

$\begin{array}{lllllllll}1 & 1 & 0 & 0 & 0 & 0 & 0 & 0 & 0 \\ 0 & 0 & 0 & 0 & 1 & 0 & 0 & 0 & 1\end{array}$


Apéndice 1. Continúa.

\begin{tabular}{|c|c|c|c|c|c|c|c|c|c|}
\hline \multirow[t]{2}{*}{ Especie } & \multicolumn{3}{|c|}{ Pastizal } & \multicolumn{3}{|c|}{$\begin{array}{c}\text { Bosque } \\
\text { Quercus-Pinus }\end{array}$} & \multicolumn{3}{|c|}{$\begin{array}{c}\text { Bosque } \\
\text { Pinus-Quercus }\end{array}$} \\
\hline & 1 & 2 & 3 & 1 & 2 & 3 & 1 & 2 & 3 \\
\hline \multicolumn{10}{|l|}{ UMBELLIFERAE (2) } \\
\hline Eryngium beecheyanum Hook. f. et Arn. & 0 & 1 & 1 & 0 & 0 & 0 & 1 & 0 & 0 \\
\hline E. carlinae Delar. & 0 & 0 & 0 & 0 & 0 & 0 & 0 & 0 & 1 \\
\hline Total & 12 & 26 & 16 & 19 & 31 & 17 & 22 & 21 & 20 \\
\hline
\end{tabular}

Apéndice 2. Densidad absoluta y relativa, cobertura relativa, frecuencia relativa y valores de importancia de las especies de plantas en los 9 cuadrados muestreados en el rancho El Durangueño. $D A$, densidad absoluta; $D R$, densidad relativa; $C R$, cobertura relativa; $F R$, frecuencia relativa y $V I$, valor de importancia.

\begin{tabular}{cccccc}
\hline & & & & & \\
Especie & $D A$ & $D R$ & $C R$ & VR \\
& $($ Ind/ha) & $(\%)$ & $(\%)$ & $(\%)$ & \\
\hline
\end{tabular}

Estrato alto

\begin{tabular}{|c|c|c|c|c|c|c|}
\hline PAS1 & Pinus chihuahuana & 197 & 100 & 100 & 100 & 300 \\
\hline \multirow[t]{5}{*}{ PAS2 } & Pinus chihuahuana & 35.67 & 20 & 84.82 & 20 & 124.82 \\
\hline & Quercus durifolia & 35.67 & 20 & 6.92 & 20 & 46.92 \\
\hline & P. engelmannii & 35.67 & 20 & 3.9 & 20 & 43.9 \\
\hline & P. cembroides & 35.67 & 20 & 3.9 & 20 & 43.9 \\
\hline & Q. arizonica & 35.67 & 20 & 0.47 & 20 & 40.47 \\
\hline \multirow[t]{3}{*}{ PAS3 } & Pinus chihuahuana & 56.7 & 37.5 & 51.25 & 25 & 113.75 \\
\hline & P. cembroides & 37.8 & 25 & 27.7 & 25 & 77.7 \\
\hline & P. engelmannii & 56.7 & 37.5 & 21.05 & 50 & 108.55 \\
\hline \multirow[t]{4}{*}{ BQP1. } & Quercus arizonica & 83 & 45.83 & 68.93 & 41.67 & 156.43 \\
\hline & Q. durifolia & 60 & 33.33 & 30.85 & 33.33 & 97.51 \\
\hline & Pinus engelmannii & 30 & 16.67 & 0.19 & 16.67 & 33.53 \\
\hline & P. chihuahuana & 8 & 4.17 & 0.02 & 8.33 & 12.52 \\
\hline \multirow[t]{4}{*}{ BQP2 } & Quercus eduardii & 194.44 & 20.83 & 27.92 & 13.64 & 62.39 \\
\hline & Q. arizonica & 155.55 & 16.67 & 18.12 & 18.18 & 52.97 \\
\hline & Q. durifolia & 155.55 & 16.67 & 16.3 & 18.18 & 51.15 \\
\hline & Q. hartwegii & 116.67 & 12.5 & 10.99 & 13.64 & 37.13 \\
\hline
\end{tabular}


Apéndice 2. Continúa.

\begin{tabular}{lccccc}
\hline Especie & $\begin{array}{c}\text { DA } \\
(\text { Ind/ha })\end{array}$ & $\begin{array}{c}\text { DR } \\
(\%)\end{array}$ & $\begin{array}{c}\text { CR } \\
(\%)\end{array}$ & $\begin{array}{c}\text { FR } \\
(\%)\end{array}$ & VI \\
\hline Q. conzattii & 77.77 & 8.33 & 10.72 & 9.09 & 28.14 \\
Arbutus xalapensis & 77.77 & 8.33 & 6.1 & 9.09 & 23.52 \\
Q. striatula & 38.89 & 4.17 & 5.23 & 4.55 & 13.95 \\
A. arizonica & 38.89 & 4.17 & 4.54 & 4.55 & 13.26
\end{tabular}

Estrato alto

\begin{tabular}{|c|c|c|c|c|c|c|}
\hline & Pinus cembroides & 38.89 & 4.17 & 0.07 & 4.55 & 8.79 \\
\hline & P. chihuahuana & 38.89 & 4.17 & 0.01 & 4.55 & 8.73 \\
\hline \multirow[t]{4}{*}{ BQP3 } & Quercus durifolia & 257.93 & 45.93 & 58.88 & 33.33 & 138.14 \\
\hline & Q. arizonica & 164.14 & 29.17 & 20.61 & 26.67 & 76.45 \\
\hline & Pinus chihuahuana & 117.24 & 20.83 & 14.8 & 33.33 & 68.96 \\
\hline & Q. grisea & 23.45 & 4.17 & 5.71 & 6.67 & 16.55 \\
\hline \multirow[t]{4}{*}{ BPQ1 } & Pinus chihuahuana & 193.63 & 62.5 & 81.62 & 40 & 184.12 \\
\hline & Quercus durifolia & 51.64 & 16.67 & 18.17 & 26.67 & 61.51 \\
\hline & P. cooperi & 25.82 & 8.33 & 0.2 & 13.33 & 21.86 \\
\hline & P. cooperi var. ornelasi & 38.73 & 12.5 & 0.01 & 20 & 32.51 \\
\hline \multirow[t]{4}{*}{ BPQ2 } & Pinus cembroides & 1209 & 75 & 83.14 & 50 & 208.14 \\
\hline & Quercus arizonica & 269 & 16.67 & 16.86 & 33.33 & 66.86 \\
\hline & Juniperus deppeana & 67 & 4.17 & 0.09 & 8.33 & 12.59 \\
\hline & P. chihuahuana & 67 & 4.17 & 0.01 & 8.33 & 12.51 \\
\hline \multirow[t]{4}{*}{ BPQ3 } & Pinus cooperi & 467 & 87.5 & 99.69 & 66.67 & 253.86 \\
\hline & Quercus conzattii & 22 & 4.17 & 0.23 & 11.11 & 15.51 \\
\hline & P. cooperi var. ornelasi & 22 & 4.17 & 0.05 & 11.11 & 15.33 \\
\hline & Q. durifolia & 22 & 4.17 & 0.04 & 11.11 & 15.32 \\
\hline
\end{tabular}

Estrato medio

$\begin{array}{llccccc}\text { PAS1 } & \text { Quercus striatula } & 17202 & 100 & 100 & 100 & 300 \\ \text { PAS2 } & \text { Quercus striatula } & 3081 & 95.83 & 96.29 & 85.71 & 277.83 \\ & \text { Arctostaphylos pungens } & 134 & 4.17 & 3.71 & 14.29 & 22.17 \\ \text { PAS3 } & \text { Quercus striatula } & 8042 & 100 & 100 & 100 & 300 \\ \text { BQP1 } & \text { Arctostaphylos pungens } & 1339 & 86.28 & 37.5 & 25 & 148.78 \\ & \text { Quercus striatula } & 446 & 13.72 & 62.5 & 75 & 151.22 \\ \text { BQP2 } & \text { Arctostaphylos pungens } & 359 & 83.33 & 75.71 & 66.67 & 225.71 \\ & \text { Arbutus arizonica } & 36 & 8.33 & 23.5 & 11.11 & 42.94\end{array}$


Apéndice 2. Continúa.

\begin{tabular}{llccccc}
\hline \multirow{2}{*}{ Especie } & $\begin{array}{c}\text { DA } \\
(\text { Ind/ha) }\end{array}$ & $\begin{array}{c}\text { DR } \\
(\%)\end{array}$ & $\begin{array}{c}\text { CR } \\
(\%)\end{array}$ & $\begin{array}{c}F R \\
(\%)\end{array}$ & VI \\
\hline \multirow{2}{*}{ BQP3 } & Lonicera pilosa & 18 & 4.17 & 0.54 & 11.11 & 15.82 \\
& A. xalapensis & 18 & 4.17 & 0.26 & 11.11 & 15.54 \\
& Arctostaphylos pungens & 280 & 58.33 & 62.36 & 18.18 & 138.87 \\
& Arbutus arizonica & 80 & 16.67 & 35.18 & 54.55 & 106.4 \\
& Lonicera pilosa & 20 & 4.17 & 1.36 & 9.09 & 14.62 \\
& Quercus striatula & 100 & 20.83 & 1.1 & 18.18 & 40.11 \\
& Especie & DA & DR & CR & FR & VI \\
& & $($ Ind/ha) & $(\%)$ & $(\%)$ & &
\end{tabular}

Estrato medio

\begin{tabular}{clccccc}
\multirow{2}{*}{ BPQ1 } & Quercus striatula & 3700 & 87.5 & 83.4 & 75 & 245.9 \\
& Arctostaphylos pungens & 352 & 8.3 & 14.24 & 12.5 & 35.04 \\
& Arbutus tessellata & 177 & 4.17 & 2.36 & 12.5 & 19.03 \\
BPQ2 & Arbutus arizonica & 1211 & 100 & 100 & 100 & 300 \\
BPQ3 & Quercus depressipes & 2616 & 20.83 & 45.33 & 25 & 91.16 \\
& Arctostaphylos pungens & 3140 & 25 & 43.76 & 25 & 93.76 \\
& Q. striatula & 6803 & 54.17 & 10.94 & 50 & 115.11 \\
\hline
\end{tabular}


